\title{
Forecasting Wholesale Prices of Maize in Tanzania Using Arima Model
}

\author{
Shadrack Elia Kibona ${ }^{1}$, and Maurice Chakusaga Mbago ${ }^{2}$ \\ ${ }^{1}$ Department of Statistics, University of Dar es Salaam, Tanzania \\ kibonashadrack14@gmai1.com \\ ${ }^{2}$ Department of Statistics, University of Dar es Salaam, Tanzania \\ mmbago@udsm. ac. tz
}

\begin{abstract}
This paper aimed at modeling and forecasting wholesale prices of maize in Tanzania using Autoregressive Integrated Moving average model for data from February 2004 to August 2017 obtained from the Bank of Tanzania. Maize crop growers lack fundamental knowledge on which periods do prices of their harvests rise up. The empirical study found $\operatorname{ARIMA}(3, \mathbf{1}, \mathbf{1})$ as the best model for maize wholesale price based on minimum Akaike's Information Criterion (AIC) and the fitted model was found to be adequate using Ljung-Box test. The forecasted prices show an increase from September 2017 to January 2018 and then to June 2018 with the maximum price in June 2018 for the forecasted horizon. The forecasted prices decrease up to January 2019 and increase thereafter.
\end{abstract}

Keywords: ARIMA, Price, Maize, Forecast and Model.

\section{Introduction}

Maize crop as one of the agricultural commodities, face high price volatility contributed by many factors ranging from variation in climatic conditions, pests and diseases, seasons of the year, prices of oil products, nature of infrastructure from production points to market places and urbanization process which consumes arable land, just to mention a few. Government policies also play a major role in price fluctuations of food crops like maize. For example when exportation of food crops is liberalized and importation of the same is banned, domestic food stocks decrease and increases their demand and consequently prices. On the other hand, import liberalization with strict exportation leads to an increase in supply and eventually a fall in prices. Researchers[5] pointed out that harvesting cycles, weather shocks, locality, and agro-ecology may systematically influence price behavior. Technological advancement has made some crops like maize and beans to have multiple usages leading to their increased demand. Needless to say, price forecasting of agricultural products is important because it can make farmers to improve production and increase real incomes [23]. However, unavailability of data, not to mention the cost associated with data collection for the multiple factors that influence agricultural food crop prices make it difficult to use econometric model [22]. Furthermore, econometric forecasting methods in agriculture have been reported not to perform well in forecasting prices and production because they are mostly affected by random shocks [4]. Researchers have observed that the large simultaneous-equations macroeconomic models constructed in the 1960s frequently have poor forecasting performance compared to fairly simple, single-variable time series models involving few parameters and compact specifications [14].

This paper, therefore, aims at fitting a time series model that can be used for forecasting wholesale prices of maize in Tanzania using the Box-Jenkins approach. In time series models the past values of the same variables give standard forecasts based on classical statistics application. The most significant point of the approach is that explanatory variables in these models are the past values of the same variable, although according to the critics of time series analysis, this is not 
necessarily the best approach mostly because of the pertinence of other economic and non-economic explanatory variables in the particular situation concerned.

Many researchers have been involved in fitting and applying models for forecasting prices of agricultural food crops worldwide. Researchers [1] forecasted retail and wholesale prices of rice by first fitting time series models using Box and Jenkins methodology in Nigeria. The series was not stationary until first differencing. ARIMA $(2,1,1)$ had a smaller mean square error and was appropriate for both imported and domestic prices. In Bangladesh, a country dominated by rice production in terms of agriculture, researchers fitted $\operatorname{SARIMA}(1,1,1) \times(0,1,1)_{12}$ which was found to be adequate based on the Ljung-Box test [15],[18]. Researchers [23] compared Autoregressive Moving Average with Autoregressive Conditional Heteroscedasticity model (ARCH) for forecasting prices of agricultural products including potatoes, onions, tomatoes, and veal. Results indicated that ARIMA model was better compared to ARCH.

Researchers [11] investigated the statistical behavior of potato wholesale prices in Agra market. Model accuracy was measured by considering the Mean Absolute Percentage Error (MAPE) and Mean Square Error (MSE) values, for which the fitted model ARIMA(2,1,1), had the smallest values of 20.6 and 102.2 respectively.

\section{Materials and Methods}

\subsection{Data}

This study used time series data from Monthly Economic Review published by Bank of Tanzania (BOT) retrieved from www.bot-tz.org for the period ranging from February 2004 to August 2017 giving 163 observations without any missing value. BOT publishes major macroeconomic statistics in Tanzania including prices of commodities. The 163 monthly observations for the price of maize satisfy the requirement of the Box-Jenkins method which requires at least 50 observations. The data collected were national average wholesale price (in Tanzania shillings) per hundred kilograms.

\subsection{Box - Jenkins Model Building}

The procedure involves preliminary transformation, model identification, estimation, diagnostic check and application of the fitted model for forecasting.

\section{Step 1: Preliminary Transformation}

ARIMA models are fitted to stationary time series because non-stationary series can only be analyzed for that particular period and cannot be generalized to other time periods. A stochastic process is said to be stationary if its mean and variance are constant over time and the value of the covariance between the two time periods depends only on the distance or gap or lag between the two time periods and not the actual time at which the covariance is computed [13]. Mathematically this means:

$$
\mathrm{E}\left(\mathrm{X}_{\mathrm{t}}\right)=\mathrm{E}\left(\mathrm{X}_{\mathrm{s}}\right)=\mu \text { and } \operatorname{Cov}\left(\mathrm{X}_{\mathrm{t}} \mathrm{X}_{\mathrm{s}}\right)=\mathrm{E}\left[\left\{\mathrm{X}_{\mathrm{t}}-\mathrm{E}\left(\mathrm{X}_{\mathrm{t}}\right)\right\}\left\{\mathrm{X}_{\mathrm{s}}-\mathrm{E}\left(\mathrm{X}_{\mathrm{s}}\right)\right\}\right]=\mathrm{R}(\mathrm{t}-\mathrm{s}) .
$$

Stationarity in mean for a time series is attained by taking the non-seasonal and seasonal difference to remove trend and seasonality respectively depending on whether the time series is non-seasonal or seasonal as proposed by Box and Jenkins [7],[6]. In practice, most time series will become stationary after taking first differences [8]. 


\section{Step 2: Model Identification}

The model identification process is performed by observing the behavior of the autocorrelation function (ACF) and partial autocorrelation function (PACF) of the stationary time series. A model is said to be a pure autoregressive of order $\mathrm{p}$ when the partial autocorrelation function cuts off after lag p. On the other hand, it is said to be a pure moving average process of order $q$ if the autocorrelation function cuts off after lag q. For the mixed model $\operatorname{ARMA}(p, q)$, both the partial autocorrelation and autocorrelation functions tail off.

One of the popular Box-Jenkins models in time series analysis is Autoregressive Integrated Moving average (ARIMA). The structure of this model is $\operatorname{ARIMA}(p, d, q)$ where $p$ is the order of the autoregressive component, $\mathrm{q}$ is the order of the moving average and $\mathrm{d}$ denotes the degree of differencing. ARIMA models are identified by examining the nature of spikes of ACF and PACF to identify components or order of the model [21].

\section{Step 3: Model Estimation}

This involves the estimation of coefficients of the model and testing their significance. The coefficients are estimated based on conditional least squares and maximum likelihood method. The processes are incorporated through statistical software used for estimation of the model parameters. Nowadays with the development of computers, estimation methods are available for varieties of statistical software used for analysis [20].

\section{Step 4: Diagnostic Checking}

The purpose of the diagnostic check is to test for model adequacy using the appropriate statistical tests and procedures. It involves checking whether the residuals generated from the fitted models are normally distributed or not. In this case, a model is said to be adequate when its residuals are random. The procedure requires examining the statistical properties of residuals which are obtained.

After fitting the model, it is necessary to plot the residuals against time $t$ and compute the correlogram of these residuals. Denoting the autocorrelation coefficient at lag $k$ for $\hat{e}_{t}$ by $r_{k}$ and if the true model is fitted, it follows therefore that $r_{k} \sim N\left(0, \frac{1}{T}\right)$ for large $T$. Values of $r_{k}$ which lie outside the interval $\pm \frac{1.96}{\sqrt{T}} \approx \pm \frac{2}{\sqrt{T}}$ (Bartlett's 95 percent confidence interval) for large value of $\mathrm{T}$ are significantly different from zero at 5 percent level of significance [9]. This may indicate that the residuals are correlated and fitted model is not appropriate. If the given model is not adequate, another model is entertained, its parameters estimated, and residuals checked for randomness.

Ljung-Box test has been suggested for determining whether the residuals are normally distributed or not [19]. The Q-Statistic which has a limiting distribution of chi-square and Ljung-Box test was developed as an extension of the Box-Pierce statistic for model adequacy checking on residuals of the fitted model was developed by [6]. These portmanteau tests consider the first $\mathrm{k}$ values of the correlogram all at once. The Q-statistic and the Ljung-Box statistic have the same limiting Chisquare distribution with $(\mathrm{k}-\mathrm{m})$ degrees of freedom which is the difference between the number of lags considered in the test and number of parameters estimated [24]. Equations (1) and (2) below present the Q-statistic and Ljung-Box statistic respectively.

$$
\begin{aligned}
& \mathrm{Q}=\mathrm{n} \sum_{\mathrm{u}=1}^{\mathrm{k}} \mathrm{r}_{\mathrm{u}}{ }^{2} \sim \chi_{\mathrm{k}-\mathrm{m}}^{2} \\
& \mathrm{LB}=\mathrm{n}(\mathrm{n}+2) \sum_{\mathrm{u}=1}^{\mathrm{k}} \frac{\mathrm{r}_{\mathrm{u}}{ }^{2}}{\mathrm{n}-\mathrm{k}} \sim \chi_{\mathrm{k}-\mathrm{m}}^{2}
\end{aligned}
$$


where, $\mathrm{m}$ is the number of parameters estimated for the model, $\mathrm{n}$ sample size (number of observations used in estimating the model), $r_{u}$ is residual autocorrelation at lag $\mathrm{u}$, and $\mathrm{k}$ is the lag length chosen in the range 15-30 for inclusion in the test.

\section{Step 5: Application of the Fitted Model for Forecasting}

This involves the use of the fitted model for forecasting the future values which can be shortterm, medium-term and long-term forecasting. The forecast values are reported with confidence intervals specified with the level of significance for out of sample forecasts.

\subsubsection{Akaike's Information Criterion (AIC)}

This was developed by a Japanese Professor [3] and is defined by:

AIC $=-2 \log$ (maximum likelihood $)+2 \mathrm{k}$, where " $\mathrm{k}$ " is the number of estimated coefficients of the fitted model [20]. AIC comprises two parts: a term which estimates deviation from the fitted model and the penalizing factor for the number of parameters to the model. A model with the minimum AIC value is the one to select among the other models fitted to the data. This criterion is a function of the residual variance and a factor which is used to penalize the number of estimated parameters.

\subsubsection{Forecast Accuracy Performance Evaluation}

For the sake of forecasting accuracy of the model statistics related to the error are computed in order to choose the best model based on their magnitudes. The common measures of forecast accuracy performance include Root Mean Squared Error (RMSE), Mean Absolute Error (MAE), Mean Absolute Percentage Error (MAPE), Mean Error (ME) and Mean Percentage Error (MPE). The first three statistics measure the magnitude of the errors and the last two statistics measure bias. A good model gives small values or values close to zero.

\subsection{Autoregressive Moving Average Models}

A time series which follows model (3) below $\mathrm{y}_{\mathrm{t}}=\alpha_{1} \mathrm{y}_{\mathrm{t}-1}+\alpha_{2} \mathrm{y}_{\mathrm{t}-2}+\cdots+\alpha_{\mathrm{p}} \mathrm{y}_{\mathrm{t}-\mathrm{p}}+\varepsilon_{\mathrm{t}}-\theta_{1} \varepsilon_{\mathrm{t}-1}-\theta_{2} \varepsilon_{\mathrm{t}-2}-\cdots-\theta_{\mathrm{q}} \varepsilon_{\mathrm{t}-\mathrm{q}} \quad$ (3) is said to be an Autoregressive moving average of order p, q. It is a mixed model of AR and MA terms. The above model can be represented in form of equation(4)given by

$\mathrm{y}_{\mathrm{t}}-\alpha_{1} \mathrm{y}_{\mathrm{t}-1}-\alpha_{2} \mathrm{y}_{\mathrm{t}-2}-\cdots-\alpha_{\mathrm{p}} \mathrm{y}_{\mathrm{t}-\mathrm{p}}=\varepsilon_{\mathrm{t}}-\theta_{1} \varepsilon_{\mathrm{t}-1}-\theta_{2} \varepsilon_{\mathrm{t}-2}-\cdots-\theta_{\mathrm{q}} \varepsilon_{\mathrm{t}-\mathrm{q}}$

\subsection{Autoregressive Integrated Moving Average Models}

The ARMA models can only be used for stationary time series data. However, in practice many time series such as those related to socio-economic and business show non-stationary behavior [16]. Time series, which contain trend and seasonal patterns, are also non-stationary in nature [12]. From an application point of view, ARMA models are inadequate to properly describe non-stationary time series, which are frequently encountered in practice. For this reason, the ARIMA model is proposed, which is a generalization of an ARMA model to include the case of non-stationarity as well.

$$
\left(1-\alpha_{1} \mathrm{Z}-\alpha_{2} \mathrm{Z}^{2}-\cdots-\alpha_{\mathrm{P}} \mathrm{Z}^{\mathrm{P}}\right) \mathrm{w}_{\mathrm{t}}=\left(1-\theta_{1} \mathrm{Z}-\theta_{2} \mathrm{Z}^{2}-\cdots-\theta_{\mathrm{q}} \mathrm{Z}^{\mathrm{q}}\right) \varepsilon_{\mathrm{t}}
$$

where $\mathrm{w}_{\mathrm{t}}=(1-Z)^{d} \mathrm{y}_{\mathrm{t}}$, is a result of differencing the original series d times [23]. 


\subsection{Seasonal Autoregressive Integrated Moving Average Models}

The ARIMA model is for non-seasonal non-stationary data. Box and Jenkins have generalized this model for analyzing time series with seasonality [8]. The proposed model is known as the Seasonal ARIMA or SARIMA. In this model, seasonal differencing of appropriate order is used to remove non-stationarity from the series. A first-order seasonal difference is the difference calculated as $z_{t}=x_{t}-x_{t-s}$ where $s$ is the length of the season. The order of seasonal model is specified as $(p, d, q) \times(P, D, Q)_{S}$ where $p$ and $q$ are the number of non-seasonal autoregressive and moving average parameters respectively, $\mathrm{P}$ and $\mathrm{Q}$ are the number of multiplicative seasonal autoregressive and moving average parameters. $\mathrm{D}$ and $\mathrm{d}$ are the degrees of seasonal and non-seasonal differencing respectively [8]. This study considered monthly data and for this case $s=12$. Its parameterization is presented in equation (6).

$$
\alpha(Z) A_{P}\left(Z^{S}\right)(1-Z)^{d}\left(Z^{S}\right)^{D} y_{t}=\theta(Z) \varphi_{Q}\left(Z^{S}\right) \varepsilon_{t}
$$

where

$$
\begin{aligned}
& \alpha(Z)=1-\alpha_{1} Z-\alpha_{2} Z^{2}-\cdots-\alpha_{P} Z^{P} \\
& \theta(Z)=\left(1-\theta_{1} Z-\theta_{2} Z^{2}-\cdots-\theta_{q} Z^{q}\right) \varepsilon_{t} \\
& A(Z)=1-A_{1} Z-A_{2} Z^{2 S}-\cdots-A_{P} Z^{S P} \text { and } \\
& \varphi(Z)=\left(1-\varphi_{1} Z^{S}-\varphi_{2} Z^{2 S}-\cdots-\varphi_{Q} Z^{S Q}\right) \varepsilon_{t}
\end{aligned}
$$

\section{Empirical Results}

Any time series is composed of four components namely: seasonal, trend, cyclic and residual. Figure 1 below shows the graphs of these components after being decomposed from the time series data. The trend looks similar to the original series.

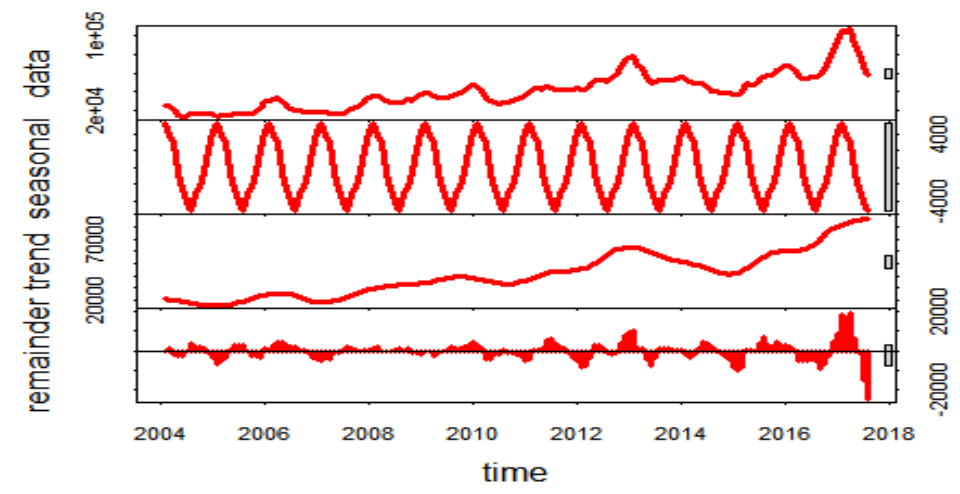

Figure 1: Decomposed Maize Price Series

\subsection{Testing for Stationarity of the Series}

An important first step for analyzing time series data is to check whether it is stationary or not and need to take an appropriate transformation in case it is not stationary to ensure it becomes stationary. Figure 1 presents a graph which shows an increasing trend where it can be predicted that the series is not stationary but it is important to supplement with some hypothesis testing.

Augmented Dickey-Fuller (ADF) test was used to test the null hypothesis that the series is not stationary. The ADF test when included five lags indicated stationary property but with 12 lags it indicated that it was not stationary at 5 percent level of significance. The ADF test involves unit root test and is usually complemented by the Kwiatkowski-Phillips-Schmidt-Shin(KPSS) test. The null hypothesis of interest under the KPSS test is that the series is stationary. The KPSS test statistic in Table 1 is 2.5369 and is less than the critical value 0.463 at 5 percent. Therefore, from both the ADF and KPSS tests, the series of Maize price is not stationary necessitating transformation, in this case, differencing to attain stationarity. 
Table 1: ADF Test and KPSS Test for Maize Price Series

\begin{tabular}{|l|l|l|l|l|}
\hline ADF Test & 5 & 12 & & \\
\hline Lag order & 3.7305 & -2.6988 & & \\
\hline ADF Test Statistic & 0.0242 & 0.2848 & & \\
\hline P-value & & & \\
\hline Alternative hypothesis: Stationary & \multicolumn{5}{l|}{} \\
\hline KPSS Test & $10 \%$ & $5 \%$ & $2.5 \%$ & $1 \%$ \\
\hline Significance level & 0.347 & 0.463 & 0.574 & 0.739 \\
\hline Critical Value & 2.5369 & \\
\hline Test Statistic & Null hypothesis: Stationary
\end{tabular}

Since the series was not stationary from the previous tests, the first difference was performed followed by testing if the series became stationary using ADF and KPSS test after first difference. Table 2 presents results for ADF and KPSS after first difference and show that the maize price series is stationary after the first difference. The p-values at lags 5 and 12 are less than 0.01 which is also less than 5 percent and lead to rejection of the null hypothesis that it is not stationary. The conclusion is therefore based on the alternative hypothesis that it is stationary from the ADF test point of view. Likewise, the KPSS test statistic in Table 2 is 0.0283 and is less than the critical value at 5 percent 0.463 which leads to failing to reject the null hypothesis at 5 percent level of significance.

Table 2: ADF Test and KPSS Test for First Differenced Maize Price Series

\begin{tabular}{|l|l|l|l|l|}
\hline ADF Test & 5 & 12 & & \\
\hline Lag order & -6.3298 & -4.3335 & & \\
\hline ADF Test Statistic & $<0.01$ & $<0.01$ & & \\
\hline P-value & \multicolumn{5}{l|}{} \\
\hline Alternative hypothesis: Stationary & $10 \%$ & $5 \%$ & $2.5 \%$ & $1 \%$ \\
\hline KPSS Test & 0.347 & 0.463 & 0.574 & 0.739 \\
\hline Significance level & 0.0283 & & \\
\hline Critical Value & \multicolumn{5}{l|}{} \\
\hline Test Statistic & Null hypothesis: Stationary \\
\hline
\end{tabular}

\subsection{Model Selection}

Model identification involves observing the properties of ACF and PACF values or their plots. From Figure 2, the possible model is $\operatorname{ARIMA}(0,1,2)$ by observing the ACF Plot and by observing the PACF plot the possible model is $\operatorname{ARIMA}(3,1,0)$. If we consider both autoregressive and moving average terms $\operatorname{ARIMA}(3,1,2)$ is a possible model. With the use of auto.arima function, $\operatorname{ARIMA}(3,1,2)$ is the best model based on Akaike`s Information Criterion.

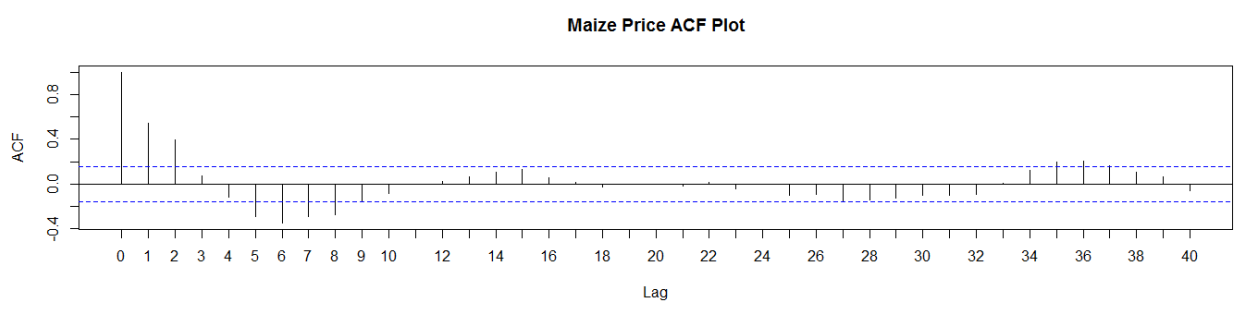

Maize Price PACF Plot

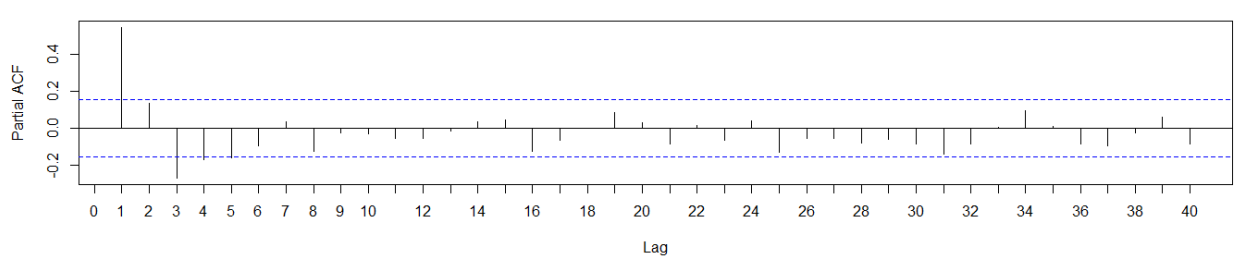

Figure 2: ACF and PACF of Differenced Maize Price 
Table 3 presents AIC for model selection and statistics used for forecast evaluation among the competing models. Forecast evaluating statistics are computed to measure the forecasting performance of the models and are based on the discrepancy between the observed values and insample forecasts. In order to fit a good model, comparisons of forecasting performance measures are of interest and the model with minimum values of these measures was selected. In this context, AIC was used as the model selection criterion and model with the minimum value of this criterion was selected among the competing models.

Table 3: Model Selection Criteria and Forecasting Performance Evaluation

\begin{tabular}{|l|l|l|}
\hline \multirow{2}{*}{ MODEL } & FORECAST PERFORMANCE MEASURE \\
\cline { 2 - 3 } & AIC & RMSE \\
\hline ARIMA $(3,1,1)$ & $\mathbf{3 0 5 2 . 0}$ & $\mathbf{2 8 5 2 . 1 9 7 0}$ \\
\hline ARIMA $(0,1,2)$ & 3074.2 & 3122.314 \\
\hline ARIMA $(3,1,0)$ & 3064.1 & 3005.458 \\
\hline ARIMA $(3,1,2)$ & 3054.56 & 2876.858 \\
\hline
\end{tabular}

$\operatorname{ARIMA}(3,1,1)$, was fitted based on minimum AIC value of 3052 and thus is the best model for maize price. It is also the best model in terms of forecasting performance with the minimum RMSE 2852.1970 in Table 3.

\subsection{Model Estimation}

The outputs in Table 4, show model summary for maize prices models. Coefficients with pvalues less than 0.05 are from a statistical point of view significantly different from zero at 5 percent level of significance. Coefficients of the fitted models in Table 4 have p-values less than 0.05 and therefore from a statistical point of view they are significantly different from zero.

Table 4: ARIMA Models Summary

\begin{tabular}{|l|l|l|l|l|l|}
\hline \multirow{2}{*}{ Coefficients } & $\mathbf{A R}(\mathbf{1})$ & $\mathbf{A R}(\mathbf{2})$ & $\mathbf{A R}(\mathbf{3})$ & $\mathbf{M A}(\mathbf{1})$ & Drift \\
\cline { 2 - 6 } & $1.2077 * * *$ & $-0.2970^{* * *}$ & $-0.4072 * * *$ & $-0.8231^{* * *}$ & 334.1631 \\
\hline Standard Error & 0.1075 & 0.1325 & 0.0814 & 0.1052 & 179.992 \\
\hline$* * *$ Means Statistically Significant at 5\%
\end{tabular}

\subsection{Diagnostic Checking}

The Ljung-Box test statistic values increase in size as the size of lag length and/or degree of freedom increase and the p-values for lags considered are greater than 0.05. From these results, the null hypothesis that the residuals generated from the fitted model are random cannot be rejected at 5 percent level of significance as presented in Table 5. Therefore, the model is adequate and suitable for forecasting.

Table 5: Ljung-Box Test

\begin{tabular}{|l|l|l|l|}
\hline Lag & Df & $\begin{array}{l}\text { Ljung-Box } \\
\text { Statistic }\end{array}$ & P-value \\
\hline 6 & 1 & 2.4214 & 0.8772 \\
\hline 12 & 7 & 4.7496 & 0.9803 \\
\hline 18 & 13 & 8.4585 & 0.9710 \\
\hline
\end{tabular}

Also from Figure 3, the graph of residuals estimated from the fitted model ARIMA $(3,1,1)$ are random. Both the autocorrelation function and partial autocorrelation function show that the residuals generated from the model are not significant at $95 \%$ confidence limits. 

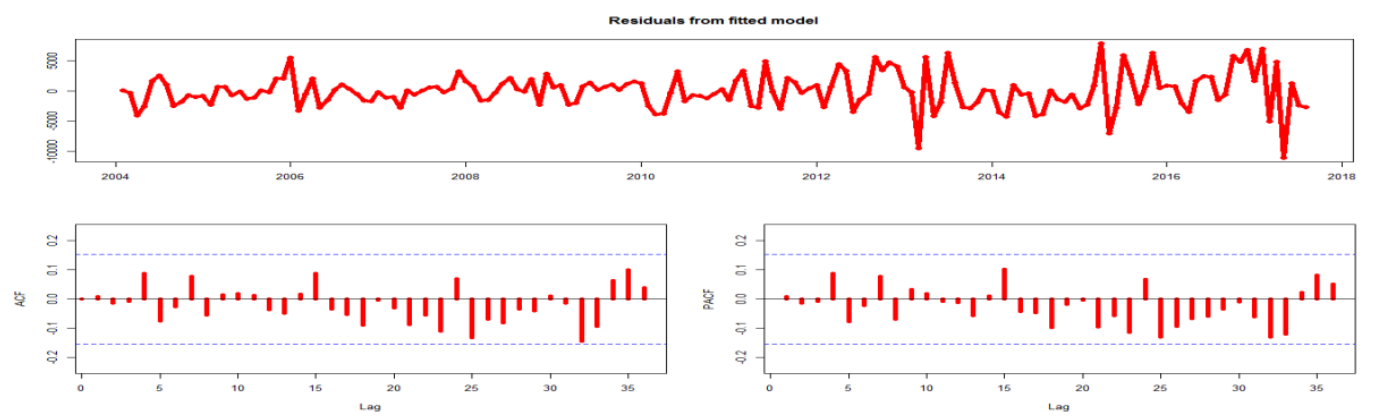

Figure 3: Residual Analysis from the Fitted $\operatorname{ARIMA}(3,1,1)$

\subsection{Forecasting Accuracy of the Fitted Model}

The selected ARIMA model for maize price performed very well with the minimum RMSE among the other model competed. The average wholesale price for maize in January and February 2018 were Tanzania shillings 49,807.5 and 58,834.3, per 100 Kilograms respectively as reported from Monthly Economic Review published by Bank of Tanzania[2]. The forecasted price using the fitted model in January and February 2018 the same year were Tanzania shillings 62,229.49 and 70,209.11 per 100 kilograms respectively (Table 6). The forecasts do not differ much from the actual price and are within the specified 95 percent confidence intervals and this gives credits to the fitted models of the food crop prices under study.

\subsection{Application of Fitted Models for Forecasting}

Model qualified after diagnostic check, was used for obtaining forecast price values of maize. According to the Box and Jenkins approach, this is the last step in ARIMA model building. Actual and forecast price values with their 80 and 95 percent confidence intervals are presented in the forecast plots (Figure 4).

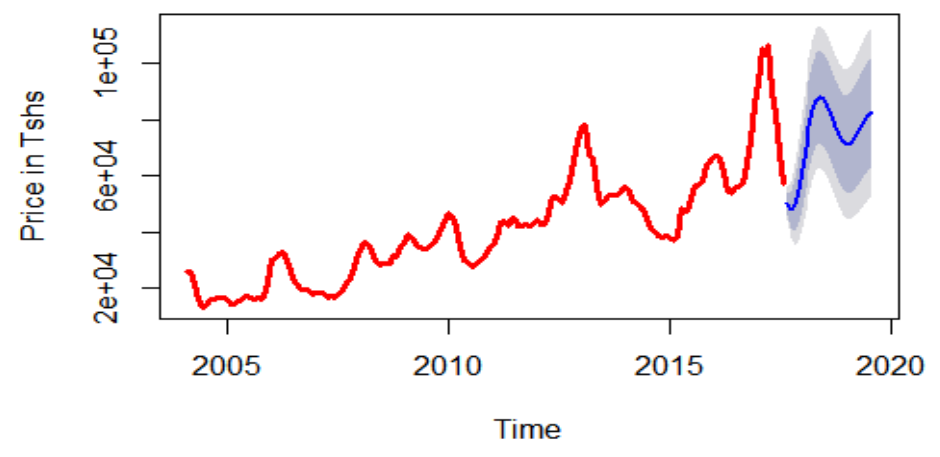

Figure 4: Time Plots for Actual and Forecasted Price of maize

Out of sample forecasts are for two years from September 2017 to August 2019. The price of maize is expected to keep increasing with time from January 2018 to September 2018 as presented in Table 6 . June 2018 records the highest price compared to other months of the year. 
Table 6: Forecast values from September 2017 to August 2019

\begin{tabular}{|lrrrrr|}
\hline Time & Point Forecast LO 80 & Hi 80 & Lo 95 & Hi & 95 \\
Sep 2017 & 50144.00 & 46419.57 & 53868.43 & 44447.98 & 55840.02 \\
Oct 2017 & 47816.98 & 41455.83 & 54178.13 & 38088.44 & 57545.52 \\
Nov 2017 & 49683.50 & 40389.40 & 58977.60 & 35469.40 & 63897.60 \\
Dec 2017 & 54927.45 & 43187.50 & 66667.40 & 36972.75 & 72882.15 \\
Jan 2018 & 62229.49 & 48550.80 & 75908.19 & 41309.73 & 83149.26 \\
Feb 2018 & 70209.11 & 55205.52 & 85212.70 & 47263.09 & 93155.13 \\
Mar 2018 & 77570.54 & 61763.82 & 93377.26 & 53396.26 & 101744.83 \\
Apr 2018 & 83327.14 & 67110.17 & 99544.10 & 58525.43 & 108128.84 \\
May 2018 & 86887.96 & 70497.56 & 103278.37 & 61821.00 & 111954.93 \\
Jun 2018 & 88096.31 & 71646.43 & 104546.19 & 62938.40 & 113254.23 \\
Ju1 2018 & 87182.25 & 70712.94 & 103651.57 & 61994.62 & 112369.89 \\
Aug 2018 & 84668.96 & 68188.18 & 101149.74 & 59463.78 & 109874.14 \\
Sep 2018 & 81245.25 & 64744.66 & 97745.85 & 56009.77 & 106480.73 \\
Oct 2018 & 77633.82 & 61082.79 & 94184.84 & 52321.21 & 102946.42 \\
Nov 2018 & 74473.95 & 57809.20 & 91138.69 & 48987.42 & 99960.47 \\
Dec 2018 & 72235.77 & 55363.45 & 89108.09 & 46431.78 & 98039.76 \\
Jan 2019 & 71173.78 & 53989.06 & 88358.49 & 44892.02 & 97455.53 \\
Feb 2019 & 71321.03 & 53736.54 & 88905.53 & 44427.87 & 98214.19 \\
Mar 2019 & 72518.46 & 54486.95 & 90549.96 & 44941.64 & 100095.27 \\
Apr 2019 & 74469.30 & 55991.05 & 92947.56 & 46209.25 & 102729.36 \\
May 2019 & 76806.46 & 57921.21 & 95691.70 & 47923.96 & 105688.95 \\
Jun 2019 & 79160.12 & 59930.40 & 98389.85 & 49750.80 & 108569.45 \\
Ju1 2019 & 81215.45 & 61708.93 & 100721.96 & 51382.81 & 111048.09 \\
Aug 2019 & 82752.65 & 63029.13 & 102476.17 & 52588.13 & 112917.17 \\
\hline
\end{tabular}

\subsection{Policy Implications}

Based on the fitted model and price forecasts for maize crop, important policy recommendations are as follows:

Storage of maize is easy and the crop can be stored for a long period of time. Once farmers harvest their crops, they are encouraged to store for selling during months with high prices. The findings show that prices of maize are forecasted to be very low in January 2018 and continue rising up to June 2018 which record the maximum price for this year. Most of the time, prices of maize rise after few middlemen have bought large quantities and stored for selling in the future. Farmers are therefore encouraged to sell during these months characterized by high prices for maximizing profit.

Farmers incur costs for inputs like fertilizer, insecticides and preservation chemicals with which they expect to compensate soon after harvesting; this is why some farmers accept selling crops at a low price. There is a need for the government to renovate and strongly establish cooperatives so that prices remain favorable to farmers even during harvesting contrary to individual buyers exploiting farmers' profit through market forces.

For the year 2019, the prices are characterized by an increasing trend from January which is carried over from the previous year. For months with forecasted prices observed high, the government should ensure the release of stocks from stores to the market through its agencies like National Food Reserve Agency (NFRA) for Tanzania and/or allowing controlled imports. This may have direct effects on price stabilization and inflation indirectly for sustainable economic growth especially for maize which is easily stored.

\subsection{Conclusion}

In this study, the best linear time series model for maize price was fitted and applied to forecast wholesale prices for a horizon of two years which equals twenty four months. The autoregressive integrated moving average model was identified and employed in forecasting these prices. The fitted model followed the general Box and Jenkins procedures from model identification, estimation, diagnostic check and application of the model to obtain forecasts for the specified horizon. Evidence 
based on this study give insights into the need for price monitoring and ensuring policy interventions for sustainable economic growth.

\section{References}

[1] A. O. Adejumo \& A. A. Momo, Modeling Box-Jenkins Methodology on Retail Prices of Rice in Nigeria, Int. J. Eng. Sci., 2(9)(2013),75-83

[2] BOT, Bank of Tanzania. Monthly Economic Review,(2018)

[3] H. Akaike, Information theory and an extension of the maximum likelihood principle, in Selected Papers of Hirotugu Akaike, Springer,(1998),199-213,https://doi.org/10.1007/978-1-46120919-5_38

[4] P. G. Allen, Economic forecasting in agriculture, Int. J. Forecast., 10(4)(1994), 601-602, https://doi.org/10.1016/0169-2070(94)90028-0

[5] J. Baffes, V. Kshirsagar \& D. Mitchell, What Drives Local Food Prices? Evidence from the Tanzanian Maize Market, World Bank Econ. Rev.,(2017), https://doi.org/10.1093/wber/lhx008

[6] G. E. Box \& D. A. Pierce, Distribution of residual autocorrelations in autoregressive-integrated moving average time series models, J. Am. Stat. Assoc, 65(332)(1970),1509-1526, https://doi.org/10.2307/2284333

[7] G. E. P. Box \& G. M. Jenkins, Times series Analysis Forecasting and Control. Holden-Day San Francisco,(1970)

[8] G. E. Box \& G. M. Jenkins, Time series analysis: forecasting and control, revised ed. HoldenDay,(1976), https://doi.org/10.1177/058310248201400608

[9] E. Bullmore et al., Statistical methods of estimation and inference for functional MR image analysis, Magn. Reson. Med., 35(2)(1996), 261-277, https://doi.org/10.1002/mrm.1910350219

[10] J. Campos, D. F. Hendry \& H.-M. Krolzig, Consistent model selection by an automatic Gets approach, Oxf. Bull. Econ. Stat., 65(s1)(2003),803-819, https://doi.org/10.1046/j.03059049.2003.00092.x

[11] D. S. Dhakre \& D. Bhattacharya, Price Behaviour of Potato in Agra Market-A Statistical Analysis, Indian Res. J. Ext. Educ., 14(2)(2016), 12-15.

[12] J. Faraway \& C. Chatfield, Time series forecasting with neural networks: a comparative study using the air line data, J. R. Stat. Soc. Ser. C Appl. Stat., 47(2)(1998), 231-250, https://doi.org/10.1111/1467-9876.00109

[13] D. N. Gujarati \& D. C. Porter, Basic Econometrics. 4th. New York: McGraw-Hill, 2003.

[14] W. H. Greene, Econometric analysis. Pearson Education India,(2003).

[15] M. F. Hassan, M. A. Islam, M. F. Imam \& S. M. Sayem, Forecasting wholesale price of coarse rice in Bangladesh: A seasonal autoregressive integrated moving average approach, J. Bangladesh Agric. Univ., 11(2)(2014), 271-276, https://doi.org/10.3329/jbau.v11i2.19925

[16] K. W. Hipel \& A. I. McLeod, Time series modelling of water resources and environmental systems, Elsevier, (1994), https://doi.org/10.1016/s0167-5648(08)x7026-1 
[17] T. F. Khan, S. M. Sayem, \&M. S. Jahan, Forecasting Price of Selected Agricultural Commodities in Bangladesh: An Empirical Study, ASA Univ. Rev., 4(1)(2010), 15-22.

[18] G. Kitagawa, Contributions of Professor Hirotugu Akaike in Statistical Science, J. Jpn. Stat. Soc., 38(1)( 2008), 119-130, https://doi.org/10.14490/jjss.38.119

[19] G. M. Ljung \& G. E. Box, On a measure of lack of fit in time series models, Biometrika,65(2)(1978), 297-303, https://doi.org/10.2307/2335207

[20] S. Makridakis \& M. Hibon, ARMA models and the Box-Jenkins methodology, J. Forecast.,16 (3)(1997),147-163,https://doi.org/10.1002/(sici)1099-131x(199705)16:3\%3C147::aid-for652\%3E3.0.co;2-x

[21] T. H. D. Ngo \&W. Bros, The Box-Jenkins methodology for time series models, in SAS Global Forum, 54(2013).

[22] S. A. Sabur and M. E. Haque, an analysis of rice price in Mymensingh town market: Pattern and forecasting, Bangladesh J. Agric. Econ., 16( 2)(1993).

[23] S. J. Sangsefidi, R. Moghadasi, S. Yazdani \& A. M. Nejad, Forecasting the prices of agricultural products in Iran with ARIMA and ARCH models, Int. J. Adv. Appl. Sci., 2(11)(2015), 54-57.

[24] R. Y. Tse, An application of the ARIMA model to real-estate prices in Hong Kong, J. Prop. Finance, 8(2)(1997),152-163, https://doi.org/10.1108/09588689710167843 